\title{
How Do Basic Computer Courses In Colleges Improve Students' Interest
}

\author{
Xin Wang ${ }^{1}$, Lei Guo ${ }^{1}$ \\ ${ }^{1}$ Mingde College, Northwestern Polytechnical University, Xi'an, 710124, China
}

Keywords: College education; Computer basic education; Students' interest

\begin{abstract}
Information era makes computer be popularized largely and its related knowledge must be mastered for students. Therefore, basic education of computer is a required course for all colleges and all majors. However, such courses do not receive ideal effect. Besides, most students lack interest and initiative in computer basic courses. This thesis will analyze such a situation, explores causes and drawbacks and puts forward measures about reform of computer basic courses, which can arouse students' interest and improve teaching effect, hoping to drive informatization quality cultivation of talent at Chinese colleges.
\end{abstract}

\section{Introduction}

As a required course of all colleges and all majors, computer basic education shoulders many duties, including improving college students' ability to apply computer, enhancing college students' personal information accomplishment and expanding their capacity of information collection and logic thinking. It can be said that computer basic education at colleges is a product needed by the society in information era. Thus, it has and will keep high importance for a long time. However, effect of computer basic education of all colleges is not idea. College students who finish the course do not show proper computer quality, which indicates that the education must have some problems and it need be improved in the aspect of educational methods to some extent.

\section{Problems existing in computer basic education at colleges}

(I) Computer basic education problems caused by students' features

College students have an obvious feature that makes them different from the ones at senior high schools, i.e., student groups come from a wide range. In detail, college students are from all corners of the country, whose original regions, schools and foundation are quite different. This causes the situation that there is huge mental difference among different students and their computer level is also different largely, which brings huge difficulty to computer teaching at colleges. Among numerous college students, students whose mentality goes against computer basic education are mainly divided into three types:

1. Students who completely have no computer foundation

Because of this kind of students' living environment, they nearly contact with computer and lack comprehension about related knowledge seriously and some of them even cannot start or turn off computer. Currently, most of colleges adopt uniform computer basic teaching, which is quite difficult for such students. In addition, they may suffer inferiority complex. As time goes by, they will lose interest in learning this course.

2. Students with partial computer knowledge

Basically, these students have had relative rich experience in using computer before. Thus, they have some comprehension about basic operation of computer. However, such students' comprehension about computer knowledge is too partial and most of them are only familiar with surfing the internet and playing games but lack the ability to use various kinds of software and own partial learning about basic knowledge and basic operation. It is a pity that many students do not cognize this point but think their computer experience and knowledge have been quite rich so that they despise computer basic course and cannot input into learning computer basic knowledge actively.

3. Students who cannot adapt to colleges' educational methods

The problem not only exists in the course Basis of Computer Engineering but also is reflected in computer basic courses seriously and has significant impacts. Students entering colleges basically have just experienced high-strength cramming exam-oriented education. Thus, they need a period to adapt to open-type education at colleges. All colleges basically establish the course Basis of 
Computer Engineering in Grade 1. It is just the period when students adapt to teaching methods, which has some negative impacts on teaching effect of the course Basis of Computer Engineering. Although the teaching method that students cannot get used to can generate some feeling of freshness, teaching methods of computer are different from that of common teaching and have strong practicalness and operability. Superposition of two differences will make students generate sense of alienation. As a result, some students who cannot adapt to this lose interest and give up this course.

(II) Computer basic education problems caused by course features

1. Knowledge features of Basis of Computer Engineering

Related knowledge of Basis of Computer Engineering is quite complicated. It not only has a large number and strong timeliness but also owns two contradictory features practicalness and abstraction. Although some operations are simple, their principles are quite complicated and abstract and cannot be understood easily. Though some knowledge can be understood easily, it is difficult to combine it with operation and its practical application is quite difficult. In addition, although some complicated knowledge points have some lateral ties, knowledge systems that have no relationship with one another also exist. The foregoing situations make teaching and learning of Basis of Computer Engineering become quite difficult. Facing lots of complicated knowledge, students flinch and lose learning interest.

2. Teaching features of Basis of Computer Engineering

Basis of Computer Engineering at colleges is a required course for all students, so teachers usually use a collective and sweeping teaching approach. They neither consider differences in students' basic level nor think of professional features of each major. As a result, teaching methods are the same, inflexible and single, which makes vitality of classroom disappear completely. The teaching method lacking pertinence is one of the reasons why students' interest is reduced and teaching effect is weakened.

\section{Students' interest in Basis of Computer Engineering at colleges}

By summarizing all kinds of problems above, we may find that, although there are various reasons, it can be attributed to the situation that students' interest is lost and they lack initiative for computer learning. Thus, reform about Basis of Computer Engineering at colleges should start with cultivating and arousing students' interest first and try to keep such an interest forever. In doing so, the foregoing problems will be solved. Cultivation of interest should be started from the following three aspects.

(I) Cultivating interest in the aspect of attitudes

To make college students' have interest, it is essential to correct their attitudes first and make them have the attitude that they are willing to face with Basis of Computer Engineering at least. Only after this can cultivation of interest be mentioned. For this, students' first impression about computer courses is critical. The first impression has quite important psychological significance, which is a basis on which students' interest is arouses. Thus, teachers should treat the first computer lesson carefully and try to lighten students' enthusiasm for computer and arouse their desire to explore related knowledge. In another word, teachers' attitudes decide students' attitudes. If teachers treat computer courses carefully, students will correct their attitudes, generate motive power to learn this course and take the first step to show interest.

(II) Cultivating interest in the aspect of modes

It is essential for teachers to combine with practical teaching situations, treat motivation of students' interest as one of the teaching objectives and improve and carry out innovation for conventional teaching modes about Basis of Computer Engineering at colleges. Teachers should select basic knowledge about computer appropriately and formulate teaching modes according to different knowledge points, which can not only enrich teaching methods and bring students feeling of freshness but also enable knowledge to be comprehended and accepted more easily. For instance, if the knowledge that need be taught has been explained specifically in teaching materials, students can understand the knowledge easily even if they rely on themselves. At this moment, it should focus on students' independent study and teachers only give some guidance and explanation about key points and prevent students from being bored. If there is no detailed explanation about the knowledge that need be taught in teaching materials or explanation is quite abstract and simple, 
teachers should give detailed explanation with pertinence. Compared with explanation, teachers should put emphasis on students' independent practice and avoid the situation that students' theories are separated from practice. If some knowledge points are too complicated, teachers may make orderly charts about such knowledge points and show them to students by using multimedia (image, animation and audio etc.). In doing so, they can not only improve classroom efficiency but also provide more knowledge for students and make knowledge can be understood and memorized more easily.

Apply the foregoing teaching modes alternately, form a comprehensive and polyfunctional systematic teaching methods, give students feeling of freshness in classroom, arouse students' enthusiasm, permeate basic knowledge about computer into each corner of classroom and attract students' interest firmly. Via changing teaching modes, abstraction can be converted into specific knowledge in the aspect of knowledge spreading, satisfy students' thirst for knowledge to the largest extent and achieve the situation that teaching is used to attract students and interest is utilized to guide students to enable them to obtain solid basis of computer engineering.

(III) Cultivating interest in the aspect of difference

Aiming at differences in different students' features, we should give difference instructions and education to them. For students with poor basis of computer engineering, we should encourage the method that mainly focuses on guidance, and teachers should be patient and use some games or software that can be operated easily to arouse students' learning interest when giving education. For students who ignore basis of computer engineering, teachers should deepen depth of knowledge according to their features, make them know their shortages and then arouse their interest in the aspect of thirst for knowledge. For students who cannot adapt to open-type education at colleges, teachers should slow teaching schedules and make such students not lose their interest in computer since they cannot adapt to new environment and new methods. For students who have had high computer level, teachers may loosen teaching limit, assign some task objectives for them, make them try to reach goals independently and avoid lost interest caused by too simple common courses by enhancing their autonomy. Interest cultivation with persistence for students with different students can built overall learning atmosphere and enable teaching effect of Basis of Computer Engineering to be enhanced effectively.

\section{Measures for improvement in computer basic education at colleges}

After being used to all things, we will lose feeling of freshness about them. If situations go on like this, interest will be lost naturally. The foregoing methods can arouse students' interest in learning computer in the beginning. However, to ensure long-term teaching effect, it is necessary to take some measures to maintain and improve interest. Thus, when students' interest is aroused, teachers should cultivate their creative ability and consciousness of innovation and enable them to keep feeling of freshness about Basis of Computer Engineering, cultivate interest and enhance interest actively. This is the best way to ensure teaching effecting of Basis of Computer Engineering at colleges for a long time.

(I) Using thirst for knowledge to cultivate creative ability

Innovation of students belongs to a kind of creative ability, and creation for new things needs enough outsight and imagination. Only in doing so can creative techniques and creative methods mastered by students be exerted. For this, thirst for knowledge is essential. Students will create new things only when they have enough curiosity for knowledge and unknown things. For this, we need achieve two aspects in basic teaching about computer. Firstly, combine computer knowledge with practical application in the society. Secondly, deepen some knowledge under the situation that students have strength or energy to spare. The two aspects can stimulate students' thirst in both width and depth, respectively, and make students' outsight and imagination be enhanced.

(II) Using typical problems to cultivate thinking ability

Independent innovation and pursuit for interest cannot be separated from excellent thinking ability. Firstly, students should realize innovation in thinking and make thinking be smooth, unique and flexible. Only after this, behavioral innovation can be talked of. Thus, basic teaching about computer must avoid constraint of fixed modes and teachers must not explain or infuse knowledge blindly or simply but insert all kinds of typical problems and make students to think by themselves to train students' innovative thinking and break traditional mindset by this method. For example, 
after systematic operation teaching, teachers may propose problem about operation to students, for instance, setting about screen saver, to make students solve problems and carry out operation by themselves. This not only cultivates innovative thinking but also improves practical operational capacity.

(III) Using practical exercise to cultivate application ability

Computer science has strong theoretical property and practicalness. In detail, practicalness is the largest expression method of the subject. Thus, if students want to cultivate their interest and innovative ability in the aspect of computer, application ability is an essential basis. In order to enhance students' application ability, it is essential to strengthen practical exercise about computer. When teachers explain theoretical knowledge, they should pay attention to combination with practice, grasp key points accurately and leave enough time for students to do independent practice and independent creation. This can achieve better learning effect.

(IV) Using transpositonal consideration to cultivate independent ability

Teachers and students carry out transpositonal consideration. On the one hand, teachers see shortages and problems of teaching from the perspective of students and improve teaching methods. On the other hand, they may ask students to teach one another and play the part of teachers. This transpositonal consideration can not only use differences in students' level to shorten the distance among them but also is more advantageous than teachers' teaching because of students' mutual comprehension. More importantly, students' identity is changed from learning into teaching, which largely enhances both subjectivity and autonomy of students.

\section{Conclusion:}

Because of complexity, wide range and flexibility of computer knowledge itself, computer teaching has the feature that it is flexible and changing. All college teachers who are responsible for computer basic education should make full use of such a feature and make classroom of computer active. As long as teachers know teaching objectives clearly, computer courses will not deviate from correct directions. Active and diversified teaching content can arouse students' learning interest to the largest extent and enable effect of computer teaching to be more obvious. This job cannot be finished by one day. Instead, interest teaching of college computer can form effective teaching system only by long-term implementation, long-term exploration and long-term improvement. If so, informatization talent can be cultivated for the country in the new era.

\section{Reference:}

[1] Wu Qun and Zhang Hanming. Situational teaching course about basics of computer application [M]. Changchun: Dongbei Normal University Press, 2009.

[2] Liu Shuhua and An Jianlong. Teachign reform and practice of colleges' information technology basic teaching under a new form [J]. Journal of Hengshui University, 2007(1).

[3] Feng Afang. Discussion about teaching reform for computer basic course of non-computer majors at colleges [J]. China Education Innovation Herald, 2010(22).

[4] Cao Hongbo. On the teaching mode combining basis of computer engineering with majors [J]. Computer Generation, 2007(9).

[5] Feng Boqin. Basic computer courses in college [M]. Xi'an: Press of Xi'an Jiaotong University, 2007.

[6] Zhang Sen. On future development of basic computer teaching at Chinese colleges [J]. Computer Education, 2005(10).

[7] Zhou Xiangying and Hu Shengzhou: Discussion on implementation plans about layered teaching of the course 'Basis of Computer Engineering' [J]. Science Mosaic, 2006(12).

[8] Wang Lili. Letting Interest knock the door to teaching about basics of computer application [J]. China Education Innovation Herald, 2012(6).

[9] Kong Chao. Information-based instructional design and practice research on computer basic courses at colleges [D]. Journal of Anhui Normal University, 2012. 